\title{
Anticipatory appetitive behavior of adrenalectomized rats under circadian salt-access schedules
}

\author{
ALAN M. ROSENWASSER \\ University of Maine, Orono, Maine \\ and \\ JAY SCHULKIN and NORMAN T. ADLER \\ University of Pennsylvania, Philadelphia, Pennsylvania
}

\begin{abstract}
Salt-hungry rats fail to develop anticipatory wheel-running activity when maintained under schedules of limited daily access to salt, in marked contrast to the robust anticipatory activity seen under food-access schedules. This suggests that the circadian oscillator underlying foodanticipatory activity is specifically related to food access and does not readily generalize to other scheduled resources. However, an alternative hypothesis is that rats are capable of anticipating daily salt-access periods, but that this anticipation is not manifest in wheel-running activity. In the present study, we maintained adrenalectomized rats under schedules of limited daily access to salt in which all salt was obtained by leverpressing. The results indicate that rats are capable of anticipating daily salt access by reference to an endogenous circadian timing mechanism. However, this behavior differs in several respects from that seen under food-access schedules.
\end{abstract}

We previously reported that rats failed to develop anticipatory increases in wheel-running activity when maintained under schedules of limited daily access to salt solutions or salty food, even when vigorous salt appetite is induced by adrenalectomy or by combined hormonal, pharmacological, and dietary treatments (Rosenwasser, Schulkin, \& Adler, 1985). This result is in marked contrast to the dramatic anticipatory locomotor activity that is seen under schedules of limited daily access to food.

The display of food-anticipatory activity is known to depend on an endogenous circadian timing system (Aschoff, von Goetz, \& Honma, 1983; Boulos, Rosenwasser, \& Terman, 1980; Coleman, Harper, Clarke, \& Armstrong, 1982; Stephan, 1981), and may reflect a biologically specialized, clock-dependent ability to learn the relationship between time of day (or, more accurately, circadian phase) and food access (Daan, 1981; Rosenwasser, 1984; Rosenwasser, Pelchat, \& Adler, 1984; Rusak, 1981). Therefore, our failure to detect similar saltanticipatory increases in locomotor activity may indicate that the mechanisms underlying the behavioral adaptation to time-restricted food availability do not readily gener-

The authors thank $B$. Stamoutsos for excellent technical assistance. This research was supported by NSF Grant BNS 82-17281 to N. Adler and A. Rosenwasser, and by Research Career Development Award MH00678 to J. Schulkin. Address correspondence to any author. A. Rosenwasser's address is Department of Psychology, University of Maine, Orono, ME 04469. J. Schulkin's address is Department of Anatomy, University of Pennsylvania School of Medicine, Philadelphia, PA 19104. N. Adler's address is Department of Psychology, University of Pennsylvania, Philadelphia, PA 19104. alize to other scheduled resources. This hypothesis is also supported by studies of behavioral activity under daily water-access schedules. Although some animals display modest to robust increases in activity preceding the time of water availability (Bolles, 1968; Bolles \& Duncan, 1969; Dhume \& Gogate, 1982; Mistlberger \& Rechtschaffen, 1985; Moore, 1980), this effect can be largely accounted for by the tendency to restrict voluntary food intake to the hours of water access under such schedules (Mistlberger \& Rechtschaffen, 1985).

Under food-access schedules, anticipatory increases $\alpha$ cur in both "spontaneous" locomotor behaviors, such as wheel-running and tilt-cage activity (Aschoff et al., 1983; Bolles \& Stokes, 1965; Coleman et al., 1982; Edmonds \& Adler, 1977; Mistlberger \& Rechtschaffen, 1984; Rosenwasser et al., 1984; Stephan, 1981), and in explicitly food-appetitive behaviors, such as leverpressing and investigatory approaches to the food cup (Aschoff et al., 1983; Bolles \& Stokes, 1965; Boulos et al., 1980; Saito \& Shimazu, 1982; Terman, Gibbon, Fairhurst, \& Waring, 1984). Indeed, the similarity between the timing of locomotor and food-appetitive behaviors under restricted food-access schedules may indicate that locomotor activity is inherently related to food-appetitive behavioral motivation, and represents a laboratory analogue of foraging, in the rat (see also Stewart, Rosenwasser, \& Adler, 1985). However, this need not be true of saltaccess schedules. For example, it is possible that rats are capable of anticipating daily periods of salt access, but do not manifest this ability in locomotor behaviors such as wheel-running activity. Therefore, the purpose of the 
present study was to determine whether anticipatory saltappetitive behavior would emerge under restricted saltaccess schedules in a situation requiring salt-hungry adrenalectomized rats to obtain small drafts of salt by leverpressing.

\section{METHOD}

\section{Subjects}

Adult male and female albino rats (Charles River CD strain) were anesthetized by intramuscular injection of ketamine $(40 \mathrm{mg} / \mathrm{kg})$ and xylazine $(13 \mathrm{mg} / \mathrm{kg})$, and administered a prophylactic dose of gentamicin. The adrenals were visualized through bilateral incisions made just posterior to the rib cage, the connective tissue between the adrenal and kidney was ligated, and the entire adrenal gland was then removed. Completeness of adrenalectomy was behaviorally assessed prior to testing by allowing the treated animals continuous access to $3.0 \% \mathrm{NaCl}$ solution for several days while they recovered in the colony room. Intact rats avoid $3.0 \% \mathrm{NaCl}$, whereas adrenalectomized animals generally ingest about 12 to $20 \mathrm{cc}$ of this solution per $24 \mathrm{~h}$.

\begin{abstract}
Apparatus
During the experiment, each animal lived individually within an operant chamber equipped with a response lever and a liquid reinforcement mechanism ("dipper"). When $\mathrm{NaCl}$ was available, each leverpress produced $5.0 \mathrm{sec}$ access to a $0.05 \mathrm{cc}$ draft of $2.0 \%$ saline, except that presses that occurred during a dipper operation had no effect. Informal observations indicated that these parameters usually allowed the animals to nearly, but not completely, ingest each draft within the allotted time. Although leverpress responses provided an accurate indication of the temporal distribution of saltappetitive behavior, this procedure did not allow for measurement of the volume ingested. All leverpresses were recorded by an online computer system and stored for subsequent analysis.
\end{abstract}

\section{Procedure}

A total of 6 animals ( 4 females and 2 males) showed sufficient home-cage $\mathrm{NaCl}$ ingestion after surgery to be considered to have sustained functionally complete adrenalectomy. These 6 animals were tested in two groups of 3 ( 2 females and 1 male), under two different sequences of salt-access and lighting conditions. In the first sequence, the animals were consecutively maintained under (1) a light:dark cycle (LD 12:12) and ad-lib salt access (12 days); (2) LD 12:12 and a 24-h salt-access schedule (initially 6 and then $3 \mathrm{~h}$ of salt access per $24 \mathrm{~h}$, during a midlight segment of the LD cycle) (21 days); (3) constant light (LL) and a 24-h salt-access schedule ( $3 \mathrm{~h}$ per 24) (12 days); (4) LL and complete salt deprivation (3 days); (5) LL and ad-lib salt access (6 days); (6) LL and an 18-h salt-access schedule ( $3 \mathrm{~h}$ per 18 ) (14 days). The animals in the second sequence were maintained under $L L$ throughout exposure to (1) ad-lib salt access (13 days); (2) a 24-h salt-access schedule (3 h per 24) (29 days); (3) an 18-h salt-access schedule ( 3 h per 18) (17 days); and (4) ad-lib salt access ( 8 days).

\section{Data Analysis}

The temporal distribution of leverpressing was analyzed using a metric originally derived for the quantification of response patterning under fixed-interval operant reinforcement schedules (Fry, Kelleher, \& Cook, 1960). This computation is based on the number of responses in each successive time bin, and is equal to 0.0 when there is no acceleration of response rate over time. As originally described, the maximum value of the metric, which would occur when all responses were restricted to the final time bin, depended on the number of time bins in the analysis. Therefore, we modified the original metric by normalizing each determination to the maximum possible under that condition. This modification allowed for the comparison of response acceleration under 18 -h and 24-h salt-access schedules: under the 18-h schedule, we used the 15 hourly nonreinforced response totals, and under the 24-h schedule, we used the 21 hourly nonreinforced response totals. In either case. an index of 1.0 indicates that all responses occurred in the last hour before salt access, whereas an index of 0.0 indicates a constant rate of responding between salt-access periods.

\section{RESULTS}

All animals readily learned to leverpress for salt. Figure 1 presents representative leverpressing records obtained from 2 female animals, one from each of the two experimental sequences. During ad-lib salt access, leverpressing was predominantly nocturnal under LD (Figure 1A), as would be expected from previous studies (Rowland, Bellush, \& Fregly, 1985). Under LL, leverpressing usually expressed weak free-running circadian rhythmicity, but in several instances no free-running rhythms could be detected (Figure 1B). Indeed, the failure to observe robust free-running rhythmicity of saltappetitive responding was somewhat surprising, since we had previously observed clear free-running rhythms in locomotor activity under the same lighting conditions (about 10-50 lx, depending on cage position). When salt access was temporally restricted, most leverpressing was concentrated during the periods of salt availability. Furthermore, modest anticipatory leverpressing could reliably be discerned, at least under LD (Figure 1A). However, anticipatory responding appeared either much weaker (Figure 1A) or absent (Figure 1B) under LL. When salt access was restricted to $3 \mathrm{~h}$ per $18 \mathrm{~h}$, no animal consistently displayed anticipatory responding (Figures $1 \mathrm{~A}$ and $1 \mathrm{~B})$.

These results are further illustrated by a quantitative analysis of nonreinforced leverpressing under the restricted salt-access schedules (Figure 2). Although the absolute number of leverpresses was rather small, a clear acceleration in responding began about 2 to $3 \mathrm{~h}$ prior to salt availability under $24-\mathrm{h}$ salt-access schedules, when salt availability was restricted to the midlight segment of the LD cycle. This acceleration was more modest and more gradual under LL, and was completely absent during 18-h salt-access schedules. The degree of anticipatory acceleration in leverpress responding was also examined using a metric originally derived for the quantification of temporal patterns of responding under fixed-interval operant reinforcement schedules (see the Method section). Figure 3 shows that this "index of acceleration" was highest under 24-h salt-access schedules and LD cycles, was consistently lower under LL, and was still lower under 18-h salt-access schedules, within individual animals.

Although rates of leverpressing do not accurately reflect the actual volume of salt ingestion across animals, analysis of the number of responses made during salt availability seems to indicate that differences in anticipatory responding between conditions were not related to differ- 

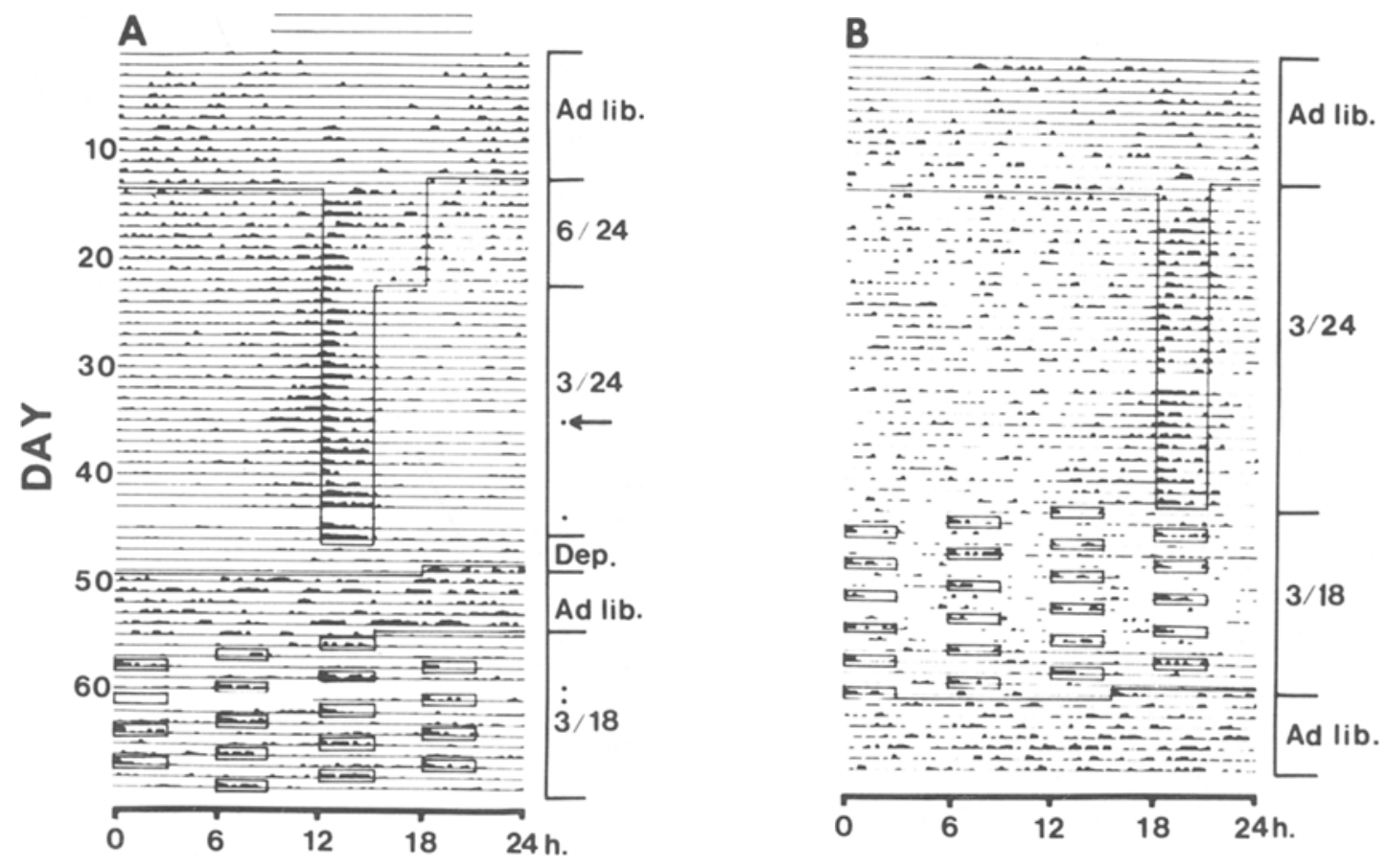

Figure 1. Raster-style record of leverpressing for 2 representative female animals over the entire course of the experiment. Time of day is indicated along the horizontal axis and successive days are indicated from top to bottom along the vertical axis. A histogram bar is plotted for each 15 - $\mathrm{min}$ time bin proportionate to the number of leverpress responses in that bin. The lines within each plot enclose the times of salt access. Salt-access conditions are indicated to the right of each record as follows: “Ad lib.," free access to salt; “6/24," 6 h salt access per $24 ; “ 3 / 24, " 3$ h salt access per $24 ;$; $3 / 18$," 3 h salt access per 18; "Dep.," complete salt deprivation. The horizontal bar above Panel $A$ indicates the light segment of the original light:dark cycle, and the arrow indicates the day on which lighting conditions were changed from light:dark 12:12 h to continuous light. The animal whose results are shown in Panel B was maintained in continuous light throughout the experiment. Asterisks indicate days on which partial or complete loss of data occurred due to recording system failure.

ences in salt intake. The number of leverpresses per 3-h salt-access period was similar for 24-h salt-access schedules under $\mathrm{LD}$ cycles $(M=150.13)$ and under $\mathrm{LL}(M$ $=165.97)$. Under 18 -h salt-access schedules, the number of responses per salt-access period was lower $(M=$ 117.82); however, when this figure is expressed as the number of responses per 24-h day, a result is obtained that is quite close to that obtained under the 24-h saltaccess schedules $(M=157.09)$. Therefore, we tentatively conclude that motivational factors related to salt appetite and salt balance were similar across these three conditions.

\section{DISCUSSION}

The results of this study demonstrate that adrenalectomized rats can display anticipatory salt-appetitive behavior under schedules of restricted daily salt access. Furthermore, the display of salt-anticipatory behavior appears to depend on an underlying circadian timing mechanism; like food-anticipatory behavior, it can occur under continuous light, and it fails to occur under noncircadian access schedules (e.g., Aschoff et al., 1983; Bolles \& Stokes, 1965; Boulos et al., 1980; Edmonds \& Adler, 1977; Stephan, 1981). However, despite these similari- ties, salt-anticipatory behavior also differs in several important ways from the anticipatory behavior seen under daily food-access schedules.

For example, the rate of leverpressing immediately prior to a scheduled food-access period frequently exceeds 100 responses per hour (Bolles \& Stokes, 1965; Boulos et al., 1980; Terman et al., 1984), whereas leverpressing rates in the present study never exceeded 20 responses per hour. This difference cannot be entirely due to motor deficits, which could have occurred as a consequence of adrenalectomy (see Leshner, 1971), since the animals in this study frequently emitted over 100 responses during the initial $15 \mathrm{~min}$ of a scheduled salt-access period. Furthermore, an earlier study showed that adrenalectomized rats given ad-lib access to salt responded about as vigorously as normal rats under restricted food-access schedules (Boulos et al., 1980). Another possibility is that the difference in magnitude of food- and salt-anticipatory responding reflects a difference in the intensity of appetitive "drive" engendered by the two procedures. We consider this possibility unlikely, since salt ingestion is a physiological necessity and has potent reinforcing properties in adrenalectomized rats (Epstein \& Stellar, 1955; Richter, 1936; Wolf, 1969). However, a definitive test 
of the hypothesis would require direct comparison between the motivational properties of food-access and saltaccess schedules.

The anticipatory behaviors seen under food- and saltaccess schedules may also differ with regard to their dependence on stimuli related to the daily light:dark cycle. Although a precise quantitative comparison is not available, inspection of published records suggests that foodanticipatory behavior is about as robust under continuous light or darkness as in the presence of light:dark cycles (e.g., Edmonds \& Adler, 1977). Similarly, the time course of food-anticipatory activity does not appear to depend on the timing of food availability relative to the light:dark cycle (Bolles, 1970). In a more fine-grained analysis, Terman et al. (1984) showed that an auditory cue that predicted the onset of food availability by inter-

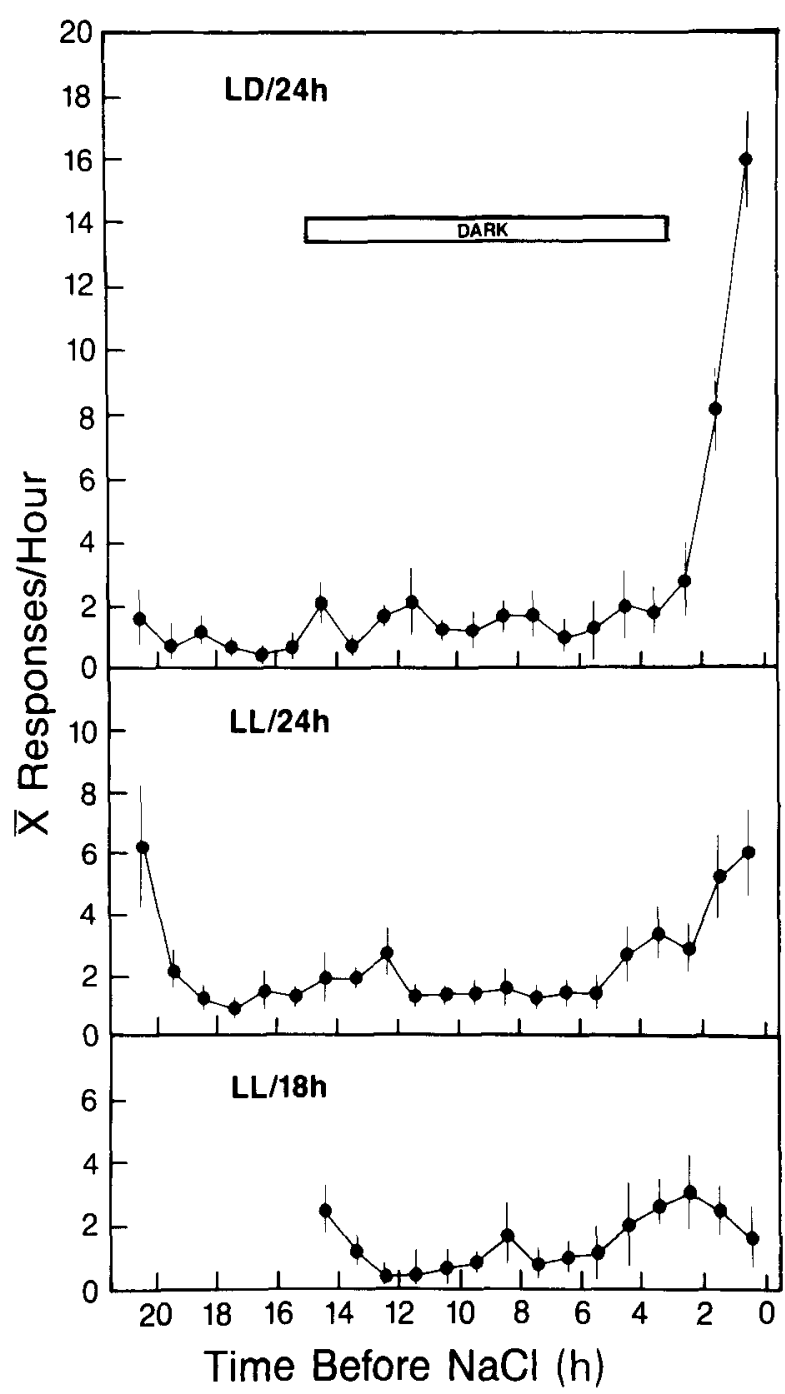

Figure 2. Mean number of nonreinforced leverpresses per hour under salt-access schedules. "LD/24h," light-dark 12:12 h and 3 h of salt access per 24; "LL/24," continuous light and $3 \mathrm{~h}$ of salt access per 24; "LL/18h," continuous light and $3 \mathrm{~h}$ of salt access per 18. Vertical lines through data points represent standard errors. $N=3(\mathrm{LD} / 24 \mathrm{~h})$ or 6 (LL/24 h and LL/18 h).

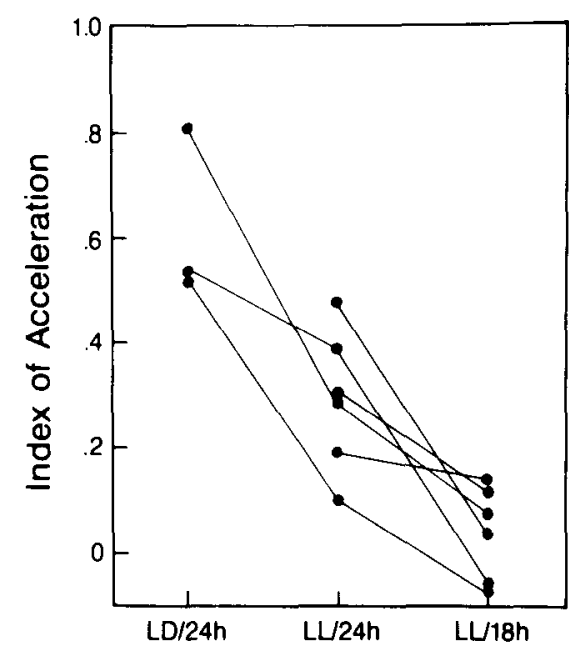

Figure 3. "Index of acceleration" for individual animals under the same three conditions as those represented in Figure 2. Lines connect determinations obtained from the same individual. The index was computed as described in Fry, Kelleher, and Cook (1960), and modified as described in the Method section. An index of 1.0 would indicate that all responses occurred in the last hour before salt access, whereas an index of 0.0 would indicate a constant rate of responding between salt-access periods.

vals ranging from a few minutes up to $4 \mathrm{~h}$ could delay the onset and reduce the magnitude of anticipatory leverpressing. However, these authors note that the exteroceptive cue did not play a predominant role in controlling the timing of anticipatory responding, since the anticipatory acceleration began considerably before cue onset under all conditions. In the present study, the onset of saltanticipatory leverpressing was delayed under light:dark cycles relative to continuous light, but the magnitude of the anticipatory acceleration was greater. Indeed, the data presented in Figure 2 suggest that our animals did not initiate leverpressing until after the dark-to-light transition of the light:dark cycle, a cue which predicted the onset of salt availability by $3 \mathrm{~h}$. Taken together, these observations suggest that the timing of food-anticipatory responding is primarily controlled by interoceptive, clockderived cues, even when exteroceptive cues are available, whereas the timing of salt-anticipatory responding is primarily controlled by interoceptive cues only when exteroceptive cues are not available.

Finally, food- and salt-anticipatory behavior may also differ in the range of responses that exhibit anticipatory increases. As described above, food-anticipatory behavior can be easily demonstrated in either spontaneous locomotor activities or specitic food-directed appetitive responses. In contrast, adrenalectomized rats display salt-anticipatory appetitive leverpressing, but fail to show salt-anticipatory wheel-running activity, providing support for the hypothesis that wheel-running may be inherently and specifically related to food-appetitive motivational systems in rats. However, the protocols typically employed to study anticipatory locomotor activities and anticipatory leverpressing differ in a potentially important feature which has been 
overlooked in the prior literature: The onset of food availability is always accompanied by some cue, usually the presentation of the food or food hopper, in studies using spontaneous activity, whereas the onset of food availability is always "silent" in studies using leverpressing. In other words, the animal must perform the measured response to determine whether food is available in the leverpressing paradigm, but not in the wheel-running paradigm. Although this procedural variable seems to have little irmpact on food-anticipatory behavior, the arguments presented above suggest that salt-anticipatory responding may be more sensitive to exteroceptive cues.

Therefore, we have conducted a preliminary study of leverpressing under continuous light and 24-h salt-access schedules in which the onset of salt availability was cued by a combined visual-auditory signal (release of the operating arm of the dipper mechanism from its locked position). Within a few days under this schedule, leverpressing was almost entirely confined to the hours of salt availability, and anticipatory responding was completely absent. This result suggests that the absence of saltanticipatory wheel-running noted in our earlier study may have been due to the cued salt access inherent in that experimental situation, rather than to the use of wheelrunning. Further studies would be necessary to clarify what may be a complex relationship among the nature of the response, the restricted resource, and the relative roles of exteroceptive and interoceptive cues in the control of anticipatory behavior.

In summary, while salt-hungry rats can anticipate a scheduled period of salt availability by reference to the phase of an endogenous circadian timing mechanism, the behavioral manifestation of this anticipation is less dramatic, and more sensitive to variations in experimental parameters, than the anticipatory behavior seen under circadian food-access schedules. Indeed, the results obtained with salt-access schedules may more closely resemble those seen under water-access schedules. While several studies have noted the occurrence of anticipatory activity under daily water-access schedules, this behavior is clearly less robust, as well as less reliable across animals, than food-anticipatory activity (Bolles, 1968; Bolles \& Duncan, 1969; Mistlberger \& Rechtschaffen, 1985). Of course, the mechanisms underlying the regulation of salt appetite and mineral balance are intimately related to those controlling thirst and fluid balance (Denton, 1982; Fitzsimons, 1979; Stricker, 1973). Indeed, several differences may be noted between these regulatory systems and those controlling food intake and energy balance. For example, food-appetitive behavior is phylogenetically more ancient than water- or salt-appetitive behavior (Schulkin, 1986). In addition, although aspects of the neural integration of energy balance are retained, neural control of water and salt balance is completely abolished in chronic decerebrate rats (Grill, Schulkin, \& Flynn, 1986; Norgren \& Grill, 1984). We believe that the present results fur- ther contribute to an appreciation of the broader psychobiological context in which salt hunger is embedded.

\section{REFERENCES}

Aschoff, J., von Goetz, C., Honma, K. (1983). Restricted feeding in rats: Effects of varying feeding cycles. Zeitschrift fur Tierpsychologie, 63, 91-111.

BoLLEs, R. C. (1968). Anticipatory general activity in thirsty rats. Journal of Comparative \& Physiological Psychology, 65, 511-513.

BoLLES, R. C. (1970). The cue value of illumination change in anticipatory general activity. Leaming \& Motivation, 1, 177-185.

Bolles, R. C., \& DUNCan, P. M. (1969). Daily course of activity and subcutaneous body temperature in hungry and thirsty rats. Physiology \& Behavior, 4, 87-89.

Bolles, R. C., Stokes, L. W. (1965). Rat's anticipation of diurnal and a-diurnal feeding. Journal of Comparative \& Physiological Psychology, 60, 290-294.

Boulos, Z., Rosenwasser, A. M., Terman, M. (1980). Feeding schedules and the circadian organization of behavior in the rat. Behavioural Brain Research, 1, 39-65.

Colfman, G. J., Harper, S., Clarke, J. D., a Armstrong, S. (1982). Evidence for a separate meal-associated oscillator in the rat. Physiology \& Behavior, 29, 107-115.

DAAN, S. (1981). Adaptive daily strategies in behavior. In J. Aschoff (Ed.), Handbook of behavioral neurobiology: IV. Biological thythms (pp. 275-298). New York: Plenum Press.

DENTON, D. A. (1982). The hunger for salt. Berlin: Springer-Verlag.

Dhume, R. A., \&ocite, M. G. (1982). Water as entrainer of circadian nunning activity in the rat. Physiology \& Behavior, 28, 431-436.

EDmonds, S. C., ADLER, N. T. (1977). Food and light as entrainers of circadian running activity in the rat. Physiology \& Behavior, 18, 915-919.

Epstein, A. N., Stellar, E. (1955). The control of salt preference in the adrenalectomized rat. Journal of Comparative \& Physiological Psychology, 48, 167-172.

Fitzsimons, J. T. (1979). The physiology of thirst and sodium appetite. Cambridge, England: Cambridge University Press.

FrY, W., Kelleher, R. T., COOK, L. (1960). A mathematical index of performance on fixed-interval schedules of reinforcement. Journal of the Experimental Analysis of Behavior, 3, 193-199.

Grill, H. J., SChULKIN, J., \& FLYNN, F. W. (1986). Sodium homeostasis in chronic decerebrate rats. Behavioral Neuroscience, 4, 534-543.

LESHNER, A. I. (1971). The adrenals and the regulatory nature of running wheel activity. Physiology \& Behavior, 6, 551-558.

Mistlberger, R. E., Rechtschaffen, A. (1984). Recovery of anticipatory activity to restricted feeding in rats with ventromedial hypothalamic lesions. Physiology \& Behavior, 33, 227-235.

Mistlberger, R. E., Rechtschaffen, A. (1985). Periodic water availability is not a potent zeitgeber for entrainment of circadian locomotor activity in rats. Physiology \& Behavior, 34, 17-22.

MoORE, R. Y. (1980). Suprachiasmatic nucleus, secondary synchronizing stimuli and the central neural control of circadian rhythms. Brain Research, 183, 13-28.

Norgren, R., Grull, H. J. (1984). Brain-stem control of ingestive behavior. In D. Pfaff (Ed.), The physiological mechanisms of motivation (pp. 99-131). New York: Springer-Verlag.

RICHTER, C. P. (1936). Increased salt appetite in adrenalectomized rats. American Journal of Physiology, 115, 155-161.

Rosenwasser, A. M. (1984). Rats remember the circadian phase of feeding. Annals of the New York Academy of Sciences, 423, 634-635.

Rosenwasser, A. M., Pelchat, R. J., \& Adler, N. T. (1984). Memory for feeding time: Possible dependence on coupled circadian oscillators. Physiology \& Behavior, 32, 25-30.

Rosenwasser, A. M., Schulkin, J., \& Adler, N. T. (1985). Circadian wheel-running activity of rats under schedules of limited daily access to salt. Chronobiology Intemational, 2, 115-119. 
Rowland, N. E., Bellush, L. L., \& Fregly, M. J. (1985). Nycthemeral thythms and sodium chloride appetite in rats. American Journal of Physiology, 249, R375-R378.

RUSAK, B. (1981). Vertebrate behavioral rhythms. In J. Aschoff (Ed.), Handbook of behavioral neurobiology: IV. Biological rhythms (pp. 183-213). New York: Plenum Press.

SAIto, M., ShimazU, T. (1982). Effects of hypothalamic lesions on an anticipatory response to feeding. In B. G. Hoebel \& D. Novin (Eds.), The neural basis of feeding and reward (pp. 115-121). Brunswick, ME: Haer Institute.

SCHULKIN, J. (1986). The evolution and expression of salt appetite. In G. de Caro, A. N. Epstein, \& M. Massi (Eds.), The physiology of thirst and sodium appetite (pp. 491-496). New York: Plenum Press.

Stephan, F. K. (1981). Limits of entrainment to periodic feeding in rats with suprachiasmatic lesions. Journal of Comparative Physiology, 143, 401-410.

Stewart, K. T., Rosenwasser, A. M., Adler, N. T. (1985). In- teractions between nocturnal feeding and wheel-running patterns in the rat. Physiology \& Behavior, 34, 601-608.

STRICKER, E. M. (1973). Thirst, sodium appetite, and complementary physiological contributions to the regulation of intravascular fluid volume. In A. N. Epstein, H. R. Kissileff, \& E. Stellar (Eds.), The neuropsychology of thirst (pp. 73-98). Washington, DC: Winston.

Terman, M., Gibbon, J., Fairhurst, F., Waring, A. (1984). Daily meal anticipation: Interaction of circadian and interval timing. Annals of the New York Academy of Sciences, 423, 470-487.

Wolf, G. (1969). Innate mechanisms for regulation of sodium intake. In C. Pfaffman (Ed.), Olfaction and Taste: Proceedings of the Third International Symposium (pp. 548-553). New York: Rockefeller University.

(Manuscript received August 24, 1987; revision accepted for publication December 21, 1987.) 